\title{
Simulation of Substrate Temperature Distribution in Diamond Films Growth on WC-Co Tools Using HFCVD Method
}

\author{
Jianguo Zhang, Yigao Yuan*, Jinjiang Zhang \\ College of Mechanical Engineering, Donghua University, Shanghai, China \\ Email: *yuanyg@dhu.edu.cn
}

How to cite this paper: Zhang, J.G., Yuan, Y.G. and Zhang, J.J. (2018) Simulation of Substrate Temperature Distribution in Diamond Films Growth on WC-Co Tools Using HFCVD Method. Journal of Materials Science and Chemical Engineering, 6, 79-87.

https://doi.org/10.4236/msce.2018.68007

Received: July 8, 2018

Accepted: August 28, 2018

Published: August 31, 2018

Copyright $\odot 2018$ by authors and Scientific Research Publishing Inc. This work is licensed under the Creative Commons Attribution International License (CC BY 4.0).

http://creativecommons.org/licenses/by/4.0/

(c) (i) Open Access

\begin{abstract}
The substrate temperature is an important factor for diamond films fabricated by hot filament chemical vapor deposition (HFCVD), which affects the grain size and quality of diamond films. In order to deposit polycrystalline diamond films with good quality on the cutting tool, the substrate temperature distribution needs to be further studied. Thus three-dimensional finite element simulations are used to investigate the temperature field with different arrangements of filaments which have profound influences on substrate temperature distribution. Based on the simulation results, the optimum parameters of distance away from drill points and gap between filaments are founded. Subsequently, experiments of depositing diamond films on WC-Co drills are conducted with the optimum values gained from the simulation results. Then, the as-fabricated diamond films are investigated by scanning electron microscopy (SEM) and Raman spectroscopy. The results indicate that the surface of drill are covered with a layer of continuous diamond films, which validate that the simulated deposition parameters are conducive and provide a new method to adjust the substrate temperature distribution in the CVD reactor for depositing diamond films.
\end{abstract}

\section{Keywords}

HFCVD, Diamond Films, Temperature Distribution, Simulation

\section{Introduction}

Diamond films are ideal materials for protective coatings because of their unique combination of excellent properties, such as high hardness, good thermal conductivity, outstanding wear resistance and chemical stability [1] [2] 
[3]. Hot filament chemical vapor deposition (HFCVD) method is suitable for fabricating diamond coated cutting tool with complex geometry because it could directly deposit diamond films on the tool surface. Typically in this method, carbon containing gas and hydrogen are introduced into the reactor and thermally activated by hot filaments, and then the active species are transported to the substrate to grow diamond films [4] [5] [6]. Many experiments have proved that the temperature distribution in the HFCVD reactor plays a determinate role on the growth rate and quality of the deposited diamond films [7] [8].

In this work, three-dimensional finite element models are built to predict the substrate temperature distribution, and optimize the arrangement of filaments with the aim of improving substrate temperature distribution in the HFCVD reactor. Subsequently, diamond films on WC-Co drills are deposited with the optimized parameters according to simulation results.

\section{Model and Simulation}

The computational model of the HFCVD reactor used in the simulation is shown in Figure 1. In the simulation, five WC-Co drills with $8 \mathrm{~mm}$ in diameter are fitted on the worktable, two tantalum filaments of $0.5 \mathrm{~mm}$ in diameter are arranged in parallel. $\mathrm{D}$ is the gap between the filaments; $\mathrm{H}$ is the distance of drill point to filaments. Before the simulation calculation, boundary conditions are defined as the following assumptions: 1) According to the Reynolds $=\mathrm{ud} / \mathrm{v}<2300$ (where, $\mathrm{u}=$ velocity based on the actual cross section area of the duct or pipe, $\mathrm{d}=$

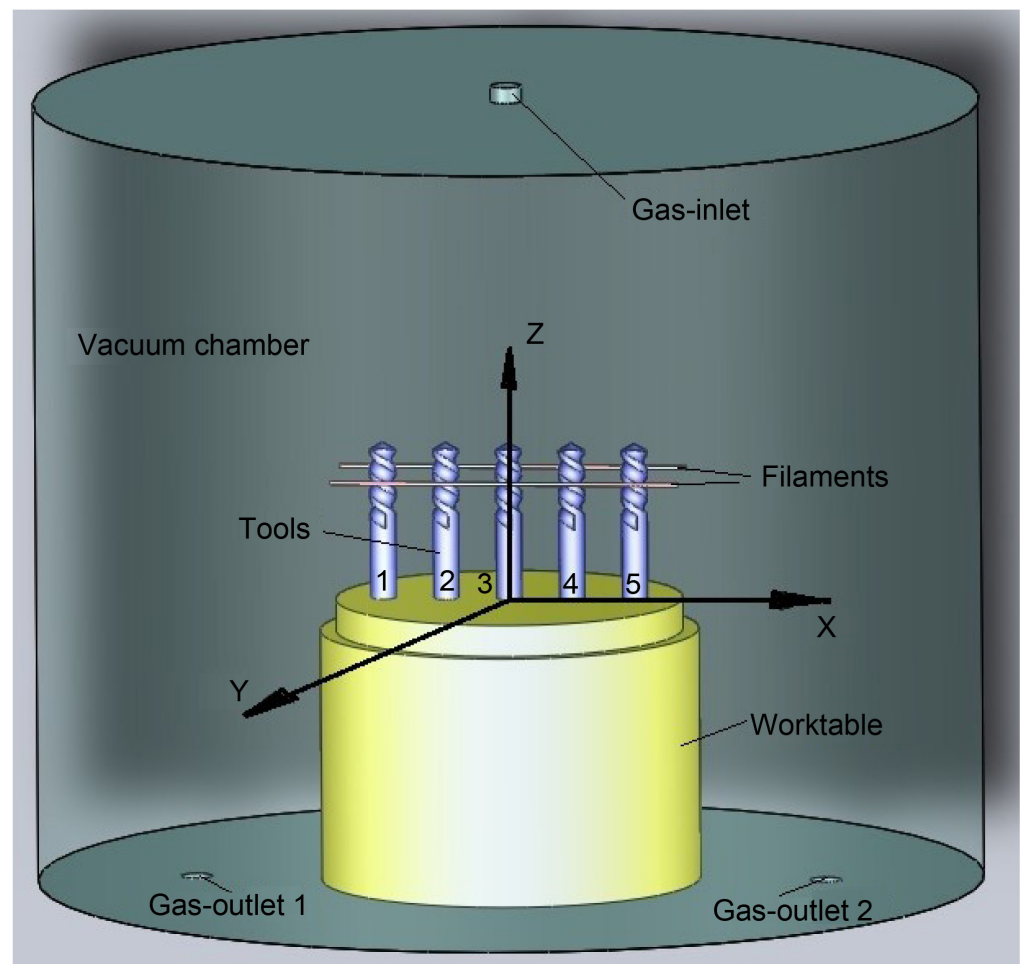

Figure 1. The computational model of the HFCVD reactor. 
hydraulic diameter, $\mathrm{v}=$ kinematic viscosity), fluid zone is defined as a laminar flow region; 2) Hydrogen is transmissive to the heat radiation, the effect of acetone is neglected due to its few content $(2 \%)$ in the gas mixtures, the reactive gas is defined as an incompressible-ideal-gas; 3) The filament temperature is $2200^{\circ} \mathrm{C}$ and other deposition parameters are constant during the whole process; 4) chemical reaction heat is neglectable [9] [10]. The initial temperature and the pressure in the HFCVD reactor are defined as $25^{\circ} \mathrm{C}$ and $3000 \mathrm{~Pa}$, respectively. The material properties used for the simulation are listed in Table 1.

\section{Simulation Results}

The parameters of filaments separation (D) and the distance of drill point to filaments $(\mathrm{H})$ have a profound effect on substrate temperature, which influences both the growth rate and the quality of the films. The effect of the two parameters is optimized separately by varying one of the two variables while holding the other as constant. Firstly, the effect of the filaments separation is examined. Figure 2 shows the temperature contours on tool substrate with the filaments separation (D) of 25, 30 and $35 \mathrm{~mm}$, in which the distance between filaments and drill point $(\mathrm{H})$ is $-10 \mathrm{~mm}$ ("minus" means the filaments lay under the drill point). The temperature of tool substrate decreases with the filaments separation increasing. The temperature did not homogeneously distribute on substrates as shown in Figure 2. The temperature in center regions (tools $2-4$ ) is much higher than that of lateral side (tools 1 and 5). Figure 3 shows the comparison of the temperature on tool 3 surface with the filaments separation (D) of 25, 30 and $35 \mathrm{~mm}$, in which $\mathrm{H}$ is $-10 \mathrm{~mm}$. Temperature distribution of tool substrate fluctuated with the change of filaments separation. The temperature decreases profoundly with increasing filaments separation. The maximum temperature of $\mathrm{D}=$ $25 \mathrm{~mm}$ reaches $950^{\circ} \mathrm{C}$ nearly $90^{\circ} \mathrm{C}$ higher than that of $\mathrm{D}=35 \mathrm{~mm}$. The fluctuation of temperature becomes smaller with the increase of filaments separation. The comparison of temperature on tool 5 in the three cases is shown in Figure 4. It shows the same situation as tool 3 , with lower surface temperature than that of tool 3 .

Figure 5 shows the variation of the temperature distribution of tool 3 with the $\mathrm{H}$ variation along the $\mathrm{Z}$ direction. The temperature reduces obviously with the

Table 1. Material properties used for the simulation.

\begin{tabular}{|c|c|c|c|c|}
\hline Component & Material & $\begin{array}{l}\text { Density } \\
{\left[\mathrm{kg} / \mathrm{m}^{3}\right]}\end{array}$ & $\begin{array}{c}\text { Thermal } \\
\text { conductivity } \\
{[\mathrm{W} /(\mathrm{m} \cdot \mathrm{K})]}\end{array}$ & $\mathrm{Cp}[\mathrm{J} /(\mathrm{kg} \cdot \mathrm{K})]$ \\
\hline Gas & Hydrogen & Incompressible-ideal-gas & 0.196 & 14,385 \\
\hline Chamber & $\begin{array}{c}\text { Stainless } \\
\text { Steel }\end{array}$ & 7750 & 17 & 502 \\
\hline Filaments & Tantalum & 16,650 & 57.56 & 135.3 \\
\hline Tools & WC-Co & 14,600 & 35 & 130 \\
\hline Worktable & Copper & 8979 & 388 & 381 \\
\hline
\end{tabular}




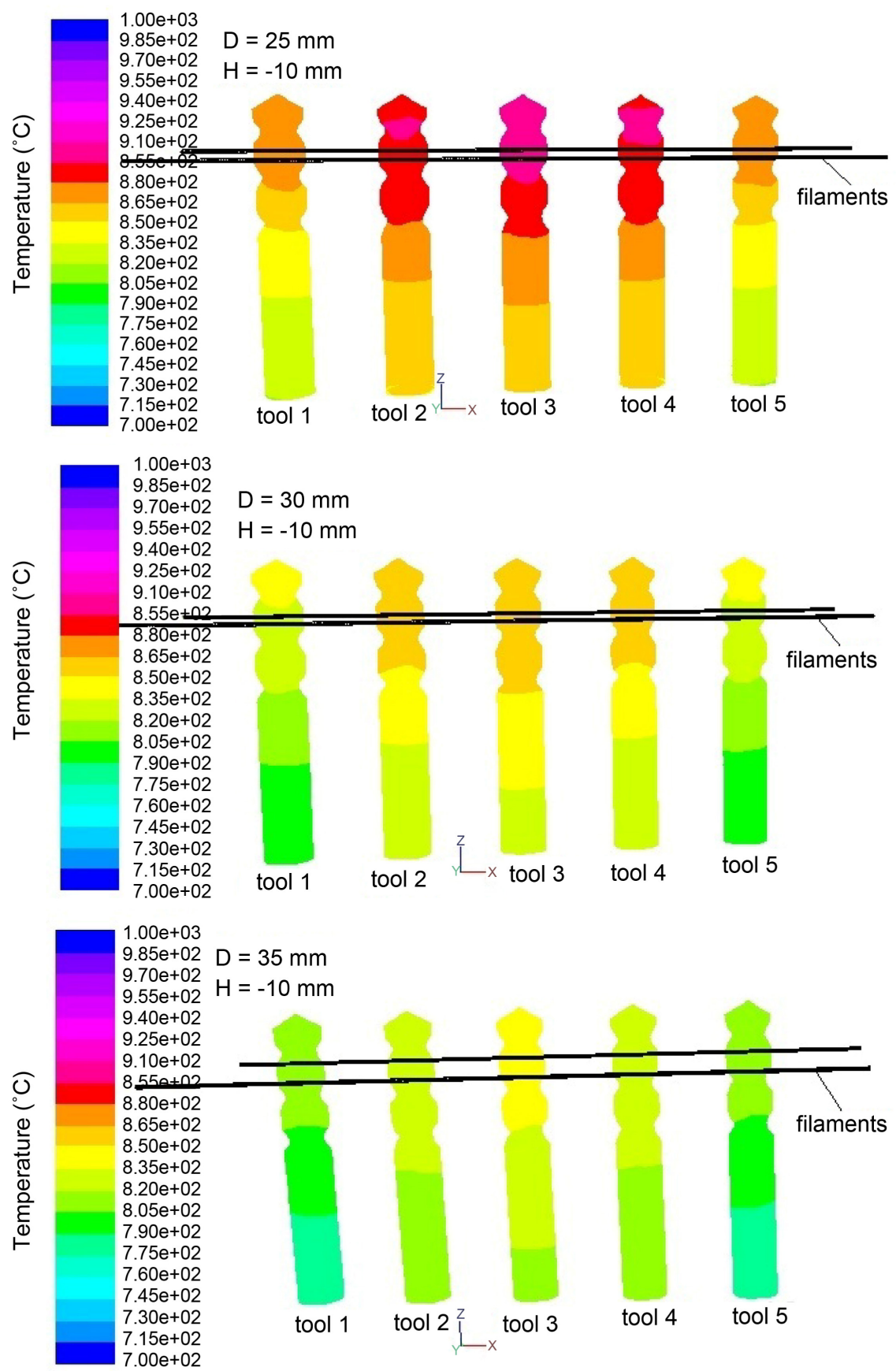

Figure 2. Temperature contours on tool substrates.

value of $\mathrm{H}$ increasing, while the fluctuation of temperature becomes smaller. The maximum temperature is about $770^{\circ} \mathrm{C}$ for $\mathrm{H}=+5 \mathrm{~mm}$ ("plus" means the filaments lay above the drill point), it is lower than that of other three cases. The area away from tools is beneficial to heat transfer, causing the lower temperature of tool surface.

Considering the above simulation results, the optimum parameters of hot filament with $\mathrm{D}=35 \mathrm{~mm}, \mathrm{H}=-10 \mathrm{~mm}$ are determined. It can be seen from Figure 3 and Figure 4 that the maximum temperature is about $855^{\circ} \mathrm{C}$ for tool 3 


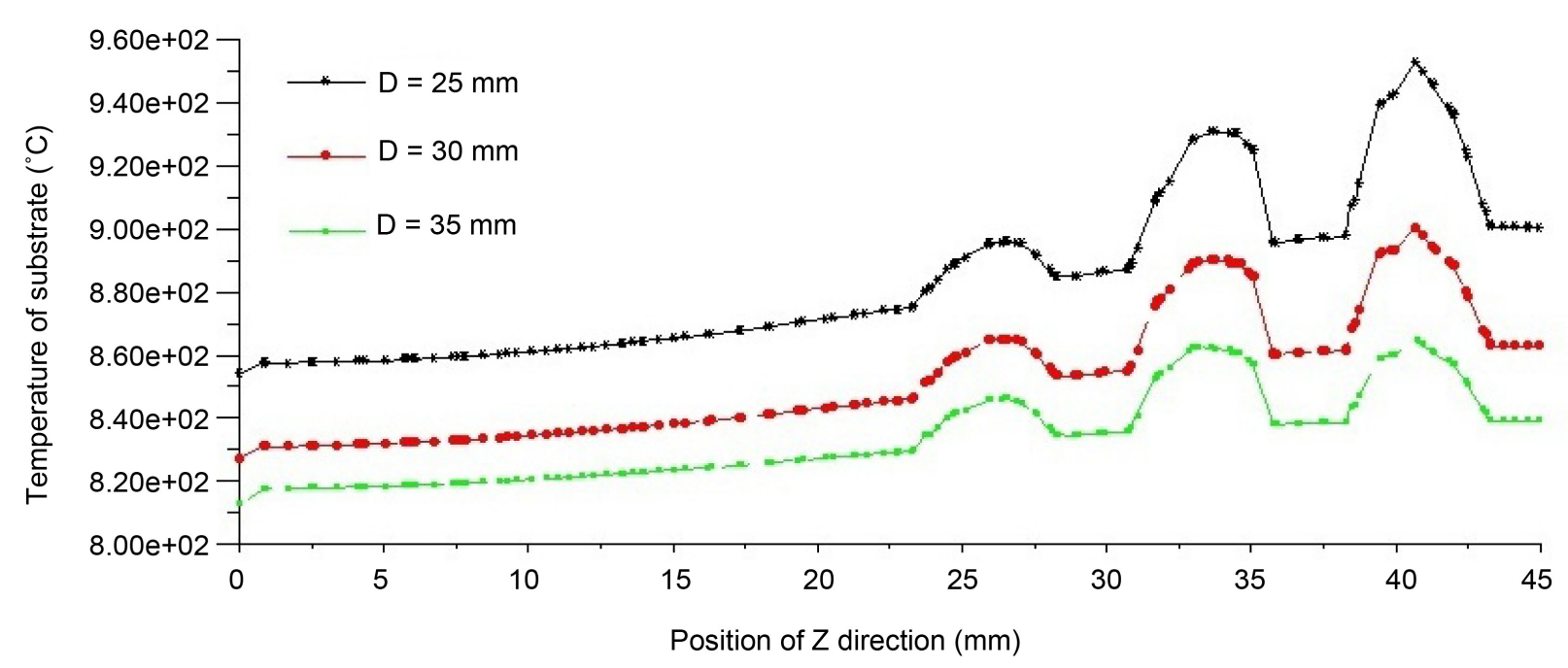

Figure 3. Temperature on surface of tool 3 with $\mathrm{H}=-10 \mathrm{~mm}$.

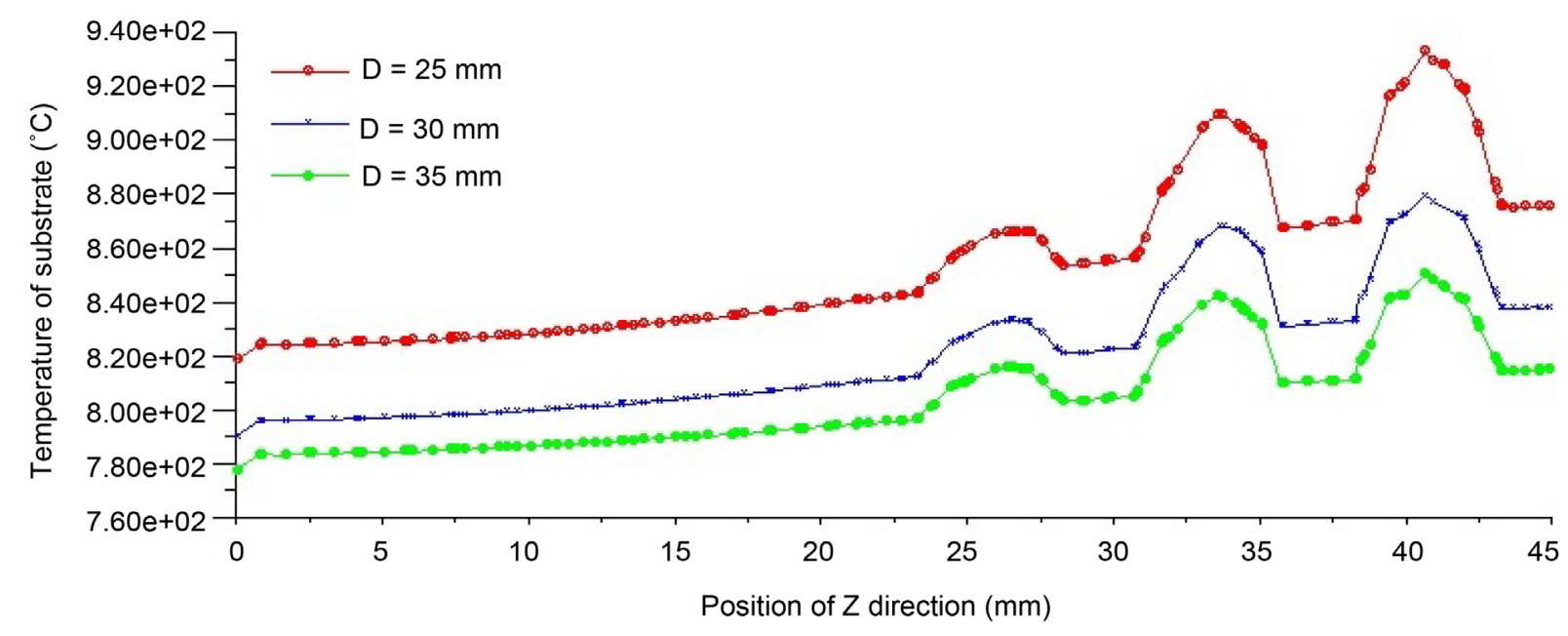

Figure 4. Temperature on surface of tool 5 with $\mathrm{H}=-10 \mathrm{~mm}$.

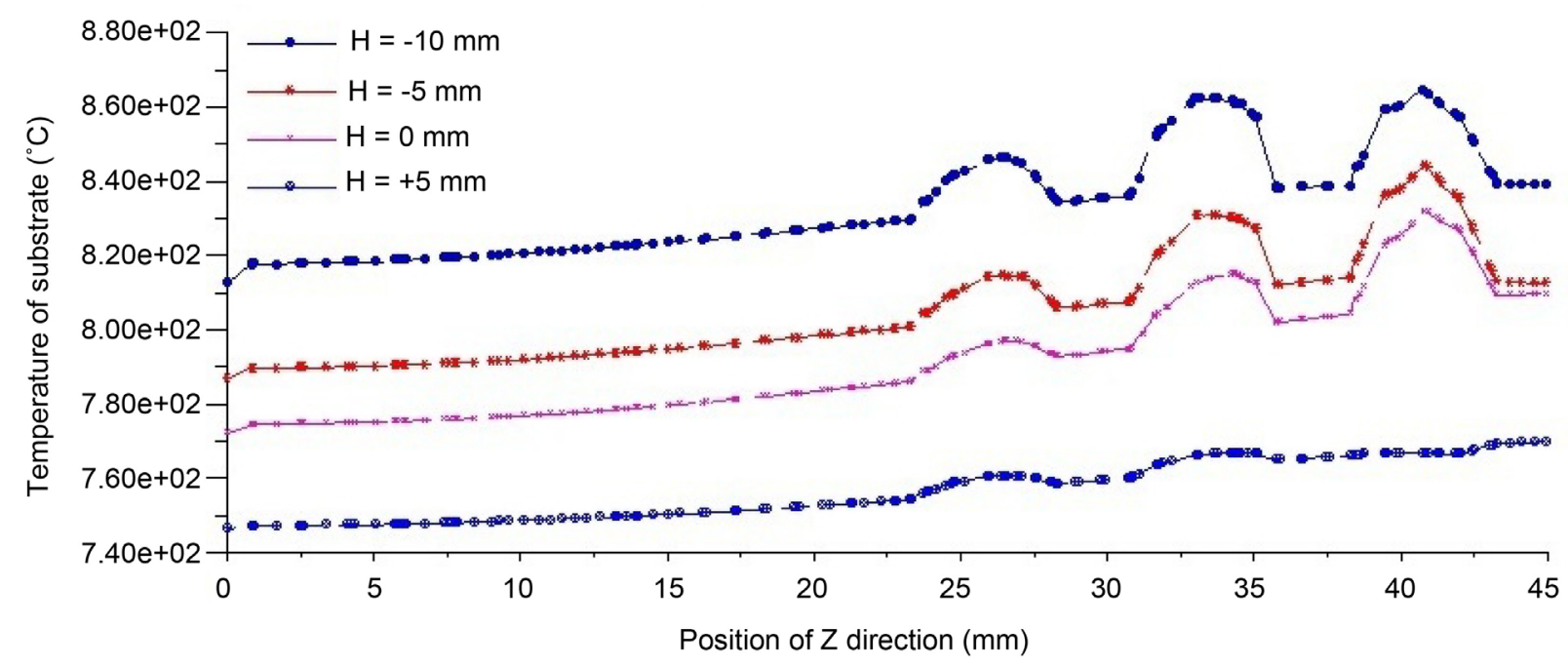

Figure 5. Temperature on surface of tool 3 with $\mathrm{D}=35 \mathrm{~mm}$. 
in the middle and $840^{\circ} \mathrm{C}$ for tool 5 in the lateral, which suggests better substrate temperature uniformity. In Figure 5, according to the curve of $\mathrm{H}=-10$, the whole tool substrate temperature is higher than those in other cases.

\section{Experimental}

The diamond coated drills are fabricated in HFCVD reactor with the optimal parameters according to the results of simulation, in which, two tantalum filaments with $0.5 \mathrm{~mm}$ in diameter are used as excitation hot filaments. They are dragged $10 \mathrm{~mm}$ below the drill point in parallel manner with $35 \mathrm{~mm}$ of the filaments separation. The WC-Co drills after being pretreated are fixed on the worktable in the middle of filaments. A gas mixture of hydrogen and acetone is used as carbon source. Other parameters are conducted as follows: reaction pressure, 2000 - $3000 \mathrm{~Pa}$; acetone concentration, 4 vol\%; bias, $0.2 \mathrm{~A}$; filament temperature during the deposition, $2200^{\circ} \mathrm{C}$; deposition time, $5 \mathrm{~h}$. The surface morphology and quality of diamond coatings are characterized by scanning electron microscopy (SEM) and Raman spectroscopy.

\section{Results and Discussion}

Scanning electron microscope is employed to investigate the surface morphology of as-deposited diamond films, as shown in Figure 6. It could be observed that the rake and flank faces of the drill are covered with a continuous layer of diamond films with grain size of $\sim 2 \mu \mathrm{m}$.

The chemical quality of the deposited diamond coating is examined by Raman spectrum, using Raman spectroscopy. The Raman spectra of the rake and flank faces on coated drill are plotted in Figure 7. It appears that detected positions present a sharp Raman band at $1332 \mathrm{~cm}^{-1}$, characteristic of high purity of $\mathrm{sp}^{3}$ bond, suggesting the high quality of the deposited diamond coating. Consequently, the simulated deposition parameters are conducive to fabricate the good quality diamond films. Figure 8 presents the cross-sectional morphology of different positions for the diamond coated tool, indicating the uniformity of the diamond coatings.

\section{Conclusions}

Substrate temperature is one of the important parameters in the process of diamond films deposition using HFCVD method. The arrangement of hot filaments in the HFCVD reactor is the key factor influencing the temperature distribution. The three-dimensional finite volume simulation is adopted to investigate the distribution of temperature during the deposition process. According to the simulation results, the arrangement of hot filament with $\mathrm{D}=35 \mathrm{~mm}$ and $\mathrm{H}=-10 \mathrm{~mm}$ is determined by obtaining the uniform substrate temperature distribution.

Experiments of depositing diamond films on WC-Co drills are conducted using the optimal parameters according to the simulation results. The results of SEM and Raman spectroscopy indicate that tool surface is covered with a 


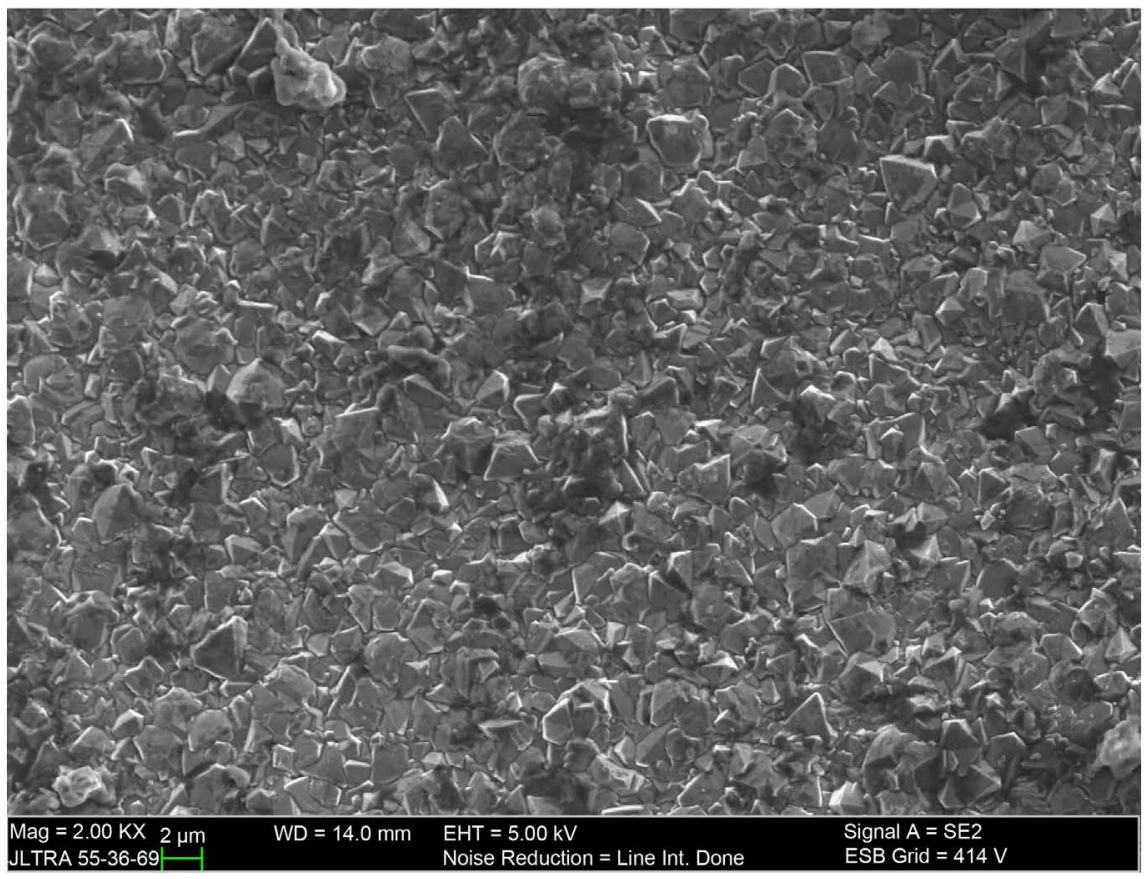

(a)

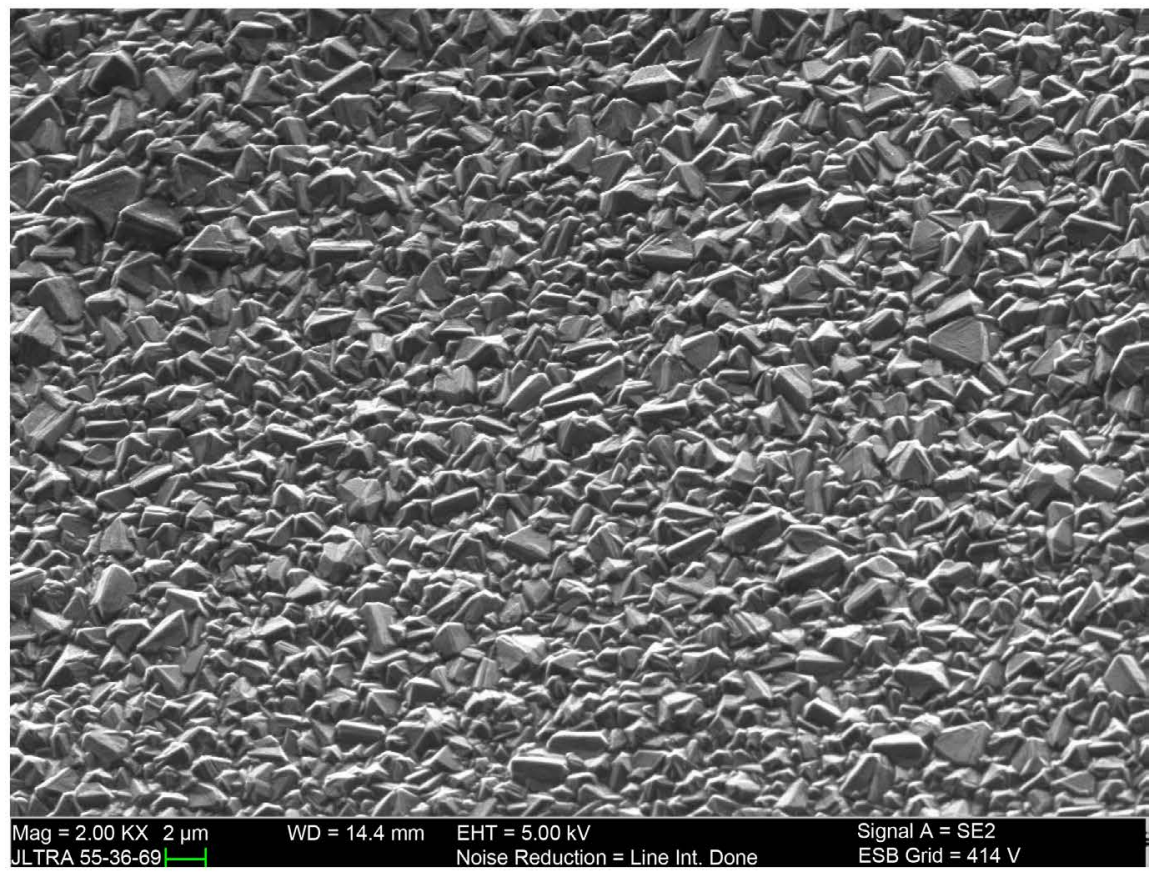

(b)

Figure 6. SEM micrographs of the surface morphology of the diamond coatings. (a) Rake face; (b) Flank face.

continuous layer of fine grained diamond films with high purity, validating that the simulated results are conducive to fabricate the high quality diamond films.

\section{Acknowledgements}

This research is sponsored by Natural Science Foundation of Shanghai (No. 


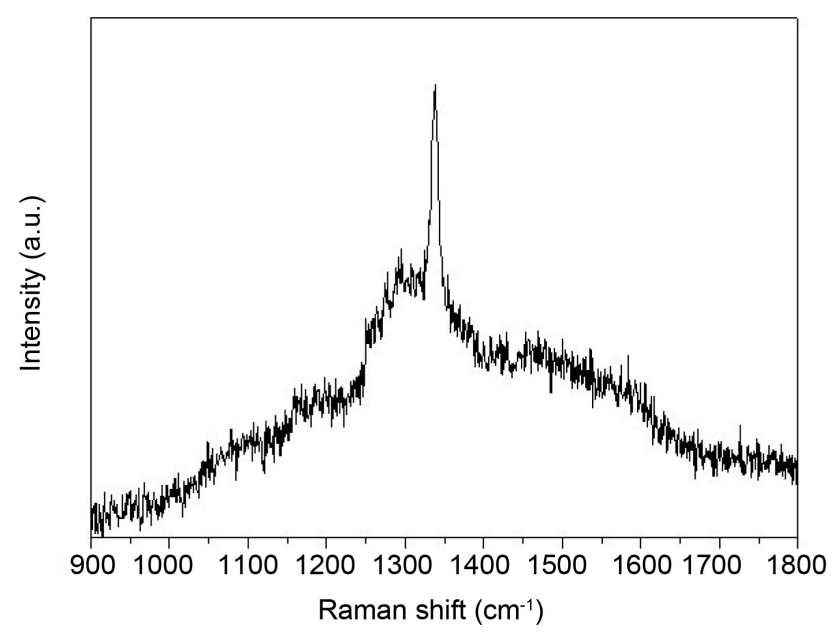

(a)

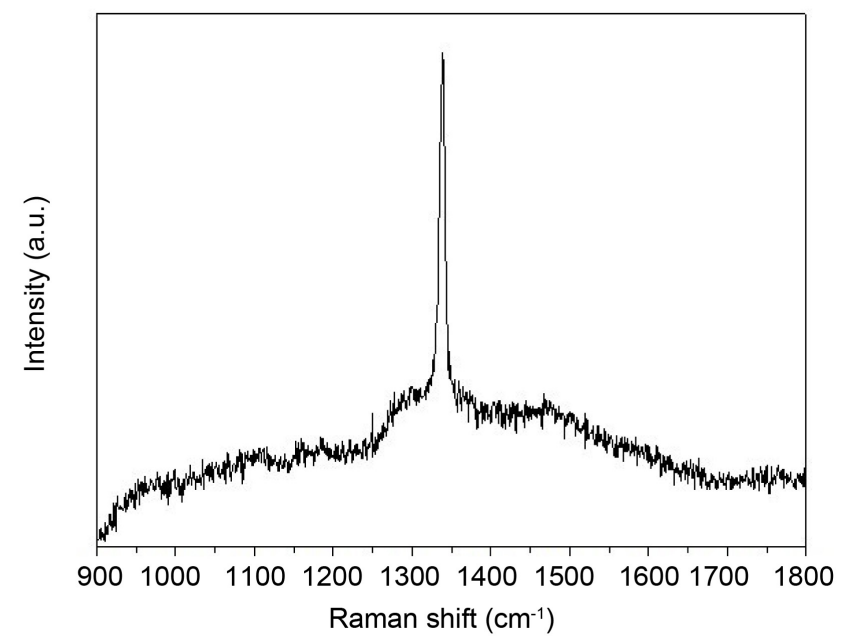

(b)

Figure 7. Raman spectra of diamond films. (a) Rake face; (b) Flank face.

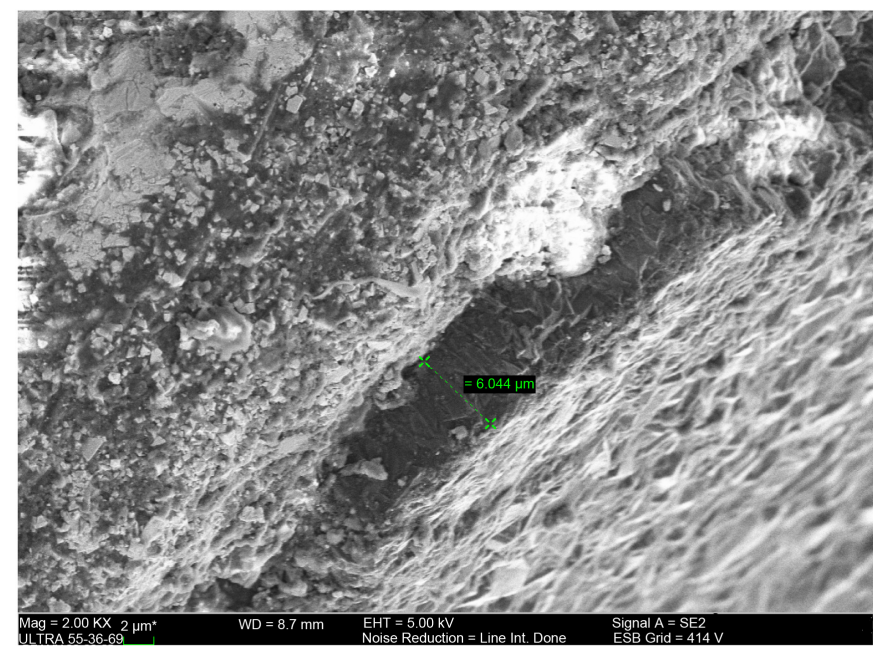

(a)

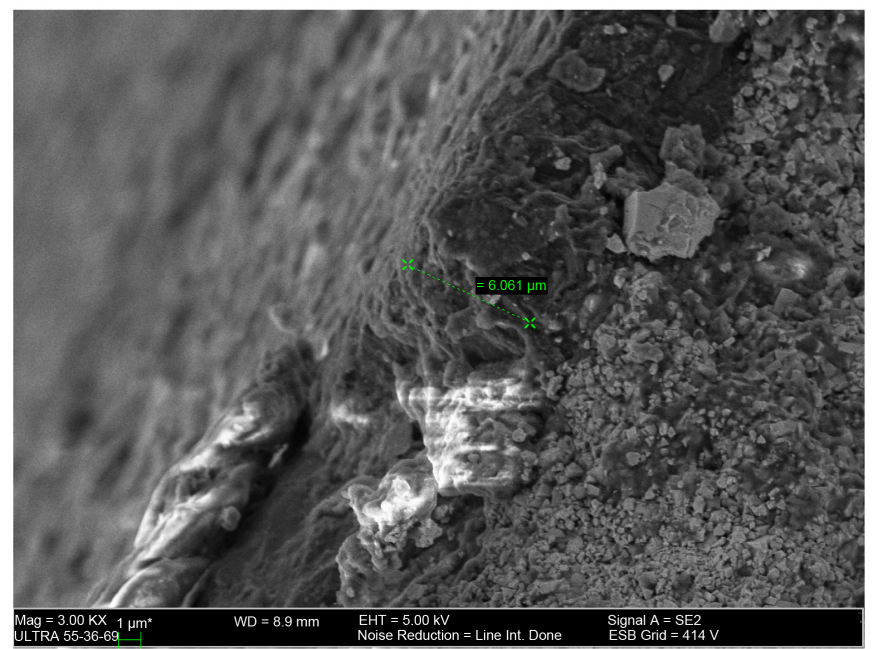

(b)

Figure 8. Cross-sectional morphology of different positions for the diamond coated tool. (a) Position I; (b) Position II. 
18ZR1401100), the Fundamental Research Funds for the Central Universities and Shanghai Key Lab of Advanced Manufacturing Environment (KT20150901).

\section{Conflicts of Interest}

The authors declare no conflicts of interest regarding the publication of this paper.

\section{References}

[1] Sun, F.H., Zhang, Z.M., Ming, C. and Shen, H.S. (2002) Fabrication and Application of High Quality Diamond-Coated Tools. Journal of Materials Processing Technology, 129, 435-440. https://doi.org/10.1016/S0924-0136(02)00635-0

[2] Fuentes-Fernandez, E.M.A., Alcantar-Peña, J.J., Lee, G., Boulom, A., Phan, H., Smith, B., et al. (2016) Synthesis and Characterization of Microcrystalline Diamond to Ultrananocrystalline Diamond Films via Hot Filament Chemical Vapor Deposition for Scaling to Large Area Applications. Thin Solid Films, 603, 62-68. https://doi.org/10.1016/j.tsf.2015.11.088

[3] Linnik, S.A., Gaydaychuk, A.V. and Baryshnikov, E.Y. (2016) Deposition of Polycrystalline Diamond Films with a Controlled Grain Size by Periodic Secondary Nucleation. Materials Today Proceedings, 3, S138-S144.

https://doi.org/10.1016/j.matpr.2016.02.024

[4] Song, G.H., Sun, C., Huang, R.F., Wen, L.S. and Shi, C.X. (2000) Heat Transfer Simulation of HFCVD and Fundamentals of Diamond Vapor Growth Reactor Designing. Surface \& Coatings Technology, 131, 500-505. https://doi.org/10.1016/S0257-8972(00)00785-4

[5] Wolden, C., Mitra, S. and Gleason, K.K. (1992) Radiative Heat Transfer in Hot-Filament Chemical Vapor Deposition Diamond Reactors. Journal of Applied Physics, 72, 3750-3758. https://doi.org/10.1063/1.352295

[6] Roy, M., George, V.C., Dua, A.K., Raj, P., Schulze, S., Tenne, D.A., et al. (2002) Feed Gas Dependence of the Surface Nanophase on HFCVD Grown Diamond Films Studied by Surface Enhanced Raman Spectroscopy. Applied Surface Science, 191, 334-337. https://doi.org/10.1016/S0169-4332(02)00215-5

[7] Barbosa, D.C., Nova, H.F.V. and Baldan, M.R. (2006) Numerical Simulation of HFCVD Process Used for Diamond Growth. Brazilian Journal of Physics, 36, 313-316. https://doi.org/10.1590/S0103-97332006000300021

[8] Barbosa, D.C., Almeida, F.A., Silva, R.F., Ferreira, N.G., Trava-Airoldi, V.J. and Corat, E.J. (2009) Influence of Substrate Temperature on Formation of Ultrananocrystalline Diamond Films Deposited by HFCVD Argon-Rich Gas Mixture. Diamond \& Related Materials, 18, 1283-1288. https://doi.org/10.1016/j.diamond.2009.05.002

[9] Zhang, T., Zhang, J., Shen, B. and Sun, F. (2012) Simulation of Temperature and Gas Density Field Distribution in Diamond Films Growth on Silicon Wafer by Hot Filament CVD. Journal of Crystal Growth, 343, 55-61. https://doi.org/10.1016/j.jcrysgro.2012.01.005

[10] Song, G.H., Yoon, J.H., Kim, H.S., Sun, C., Huang, R.F. and Wen, L.S. (2002) Influence of Hot Filaments Arranging on Substrate Temperature during HFCVD of Diamond Films. Materials Letters, 56, 832-837. https://doi.org/10.1016/S0167-577X(02)00623-7 